\title{
RÉGIMEN JURÍDICO DE LA ACCIÓN DE ACCESO A LA INFORMACIÓN PÚBLICA EN EL URUGUAY
}

\author{
ACTION STATUS OF ACCESS TO PUBLIC INFORMATION IN
}

URUGUAY

Pablo Schiavi Recebido em: 29/07/2016
Aceito em: 20/09/2016

psschiavi@hotmail.com

\begin{abstract}
Resumo: En este artículo se pretende mostrar la importancia del acceso a la información pública, que es un derecho humano fundamental. El estudio se basa en los pilares fundamentales del derecho y las recientes medidas adoptadas por el Estado.
\end{abstract}

Palavras-chave: Acesso a la Información. Derecho Fundamental.

Abstract: This article seeks to show the importance of access to public information, it is a fundamental human right. The study builds on the fundamental pillars of law and the recent measures taken by the State.

Keywords: Access to public information. Fundamental Right.

\section{PILARES FUNDAMENTALES DEL ACCESO A LA INFORMACIÓN PÚBLICA}

Una breve referencia a los pilares fundamentales del derecho de acceso a la información pública es una cuestión preliminar y hasta obligatoria para tomar real dimensión y consideración de que estamos ante un derecho humano fundamental y que, por lo tanto, toda solicitud en tal sentido, canalizada a través del procedimiento administrativo especial (al que llamamos "ruta hacia la información pública”), deberá ser tratada y considerada como tal. (SCHIAVI, 2014).

Y este es no es un tema menor o redundante. Es un tema central, de principios. Y más a la luz de las respuestas y evasivas esgrimidas por el Estado ante situaciones puntuales planteadas que han tomado estado público en los últimos tiempos.

Como un desprendimiento del derecho a la información, emerge actualmente con plena autonomía el derecho de acceso a la información pública, apunta Marcela I. BASTERRA, citada por Carlos E. DELPIAZZO(2009), quien sostiene que tres principios generales convocan a la accesibilidad de la información de los entes públicos, siempre que la misma no se encuentre limitada mediante ley dictada por razones de interés general en atención a fines específicos (tal como ocurre con el secreto militar, el secreto estadístico y el secreto tributario).

Tales principios, a juicio del distinguido profesor, son, en primer lugar, el principio de publicidad del obrar administrativo; en segundo lugar e íntimamente asociado al principio de la publicidad, el principio de transparencia y en tercer lugar, y desde la perspectiva tecnológica, el principio de participación. De acuerdo a dicho principio, existiendo accesibilidad real, corresponde que los habitantes sean informados y consultados en los asuntos que les conciernen (DELPIAZZO, 2009).

El Comité Jurídico Interamericano plasma los "Principios sobre el Derecho de Acceso a la Información" (CJI/RES. 147 (LXXIII-O/08, 7 de agosto de 2008, Río de Janeiro, Brasil) sobre el 
derecho de acceso a la información, los cuales están interrelacionados y deben interpretarse de forma integral (SCHIAVI, 2012).

Al respecto simplemente insistir con lo enunciado en el primer principio, en tanto establece los pilares fundamentales de este derecho: "1. Toda información es accesible en principio. El acceso a la información es un derecho humano fundamental que establece que toda persona puede acceder a la información en posesión de órganos públicos, sujeto solo a un régimen limitado de excepciones, acordes con una sociedad democrática, y proporcionales al interés que los justifica. Los Estados deben asegurar el respeto al derecho de acceso a la información, adoptando la legislación apropiada y poniendo en práctica los medios necesarios para su implementación".

En materia del acceso a la información pública, señala Cristina VÁZQUEZ PEDROUZO (2011, p. 61) que "el principio más fuertemente involucrado es el de la transparencia de la gestión pública, concepto que se instala con fuerza en la preocupación de la comunidad, sobre todo en la década de los noventa". En el trabajo citado la prestigiosa jurista hace un valiosísimo estudio de los principios rectores vinculados en materia de acceso a la información pública y de protección de datos personales y se plantea la cuestión de cómo resolver los probables conflictos entre dichos principios, considerando la necesidad de conciliar el interés público comprometido con el derecho a la información y la transparencia de la gestión pública, con la tutela de la intimidad y la privacidad que son inherentes a la persona humana.

El libre acceso de las personas a las fuentes de información pública es un derecho humano universal y un principio democrático inherente al derecho a la información, a la libertad de expresión y de prensa.

El acceso a la información pública contribuye a: la transparencia de la gestión pública; el combate a la corrupción y la cultura del secreto como práctica; la eficiencia en el manejo de la labor pública; la participación ciudadana en la forma de decisiones de interés público. (http://www.unesco.org/new/es/sanjose/communication-information/free-and-universal-access-toinformation/)

\section{LA CAÍDA DEL SECRETO DE ESTADO: ACCESO A LA INFORMACIÓN PÚBLICA COMO REGLA}

Hasta hace poco, "el secreto de Estado" ha sido por mucho tiempo la regla, en su relación con los particulares. Con el triunfo del neoconstitucionalismo que nos hace ver el ordenamiento jurídico desde la óptica de los derechos humanos, ese "secreto de Estado" tiende a desaparecer. El derecho al acceso a la información pública se impone, adquiere autonomía y comienza a ser recogido expresamente por las constituciones más modernas, como la española de 1978 (DURÁN MARTíNEZ, 2012).

Con acierto, señala Augusto DURÁN MARTíNEZ (2012, p. 96) que "se ha visto el fundamento del derecho de acceso a la información pública en la necesidad de transparencia y como una exigencia democrática. En definitiva, este es un derecho que hace a la esencia del Estado Social y Democrático de Derecho o, como también se dice del Estado Constitucional".

Revista do Direito [ISSN 1982-9957]. Santa Cruz do Sul, v. 2, n. 49, p. 70-95, maio/ago. 2016. https://online.unisc.br/seer/index.php/direito/index 
El artículo $2^{\circ}$ de la Ley № 18.381 de 17 de octubre de 2008 define la información pública: "Se considera información pública toda la que emane o esté en posesión de cualquier organismo público, sea o no estatal, salvo las excepciones o secretos establecidos por ley, así como las informaciones reservadas o confidenciales".

Por su parte el artículo 4ํ dispone que "Se presume pública toda información producida, obtenida, en poder o bajo control de los sujetos obligados por la presente ley, con independencia del soporte en el que estén contenidas".

Por lo tanto, de la redacción de ambos artículos, surge que información pública es toda la que emane o esté en posesión de cualquier organismo público, sea o no estatal (presumiendo como tal la información producida, obtenida, en poder o bajo control de los sujetos obligados por la presente ley, con independencia del soporte en el que estén contenidas), salvo la excepciones expresamente determinadas (SCHIAVI, 2012).

De acuerdo a los "Los Principios del Comité Jurídico Interamericano (2008)" referidos, el derecho de acceso a la información refiere a toda información significante, cuya definición debe ser amplia, incluyendo toda la que es controlada y archivada en cualquier formato o medio por los Estados.

$\mathrm{Y}$ en especial el principio $\mathrm{N}^{\circ} 8$, aplicable plenamente al objeto del presente trabajo, que dispone expresamente que "Todo individuo debe tener el derecho de recurrir cualquier negativa $u$ obstrucción de acceso a la información ante una instancia administrativa. También debe existir el derecho de apelar las decisiones de este órgano administrativo ante los tribunales de justicia".

\section{PROCEDIMIENTO ADMINISTRATIVO ESPECIAL}

A modo de repaso, referimos a que la ley uruguaya consagra un procedimiento administrativo (artículos 13 a 18) y una acción jurisdiccional específica para el acceso a la información pública (SCHIAVI, 2011).

Cristina VÁZQUEZ (2011, p. 86) señala que "para denominar la vía de garantía tendiente a obtener del Juez competente una decisión que permita el acceso a determinada información, se emplea la expresión "habeas data impropio", reservando "habeas data propio" o simplemente "habeas data" para el caso en que la acción refiere al ejercicio del derecho a la protección de datos personales".

El agotamiento del procedimiento administrativo de acceso a la información pública es requisito de admisibilidad de la acción de acceso a la información. En caso de que se concurra a la sede judicial sin haberse agotado previamente el procedimiento administrativo de acceso a la información pública, el Tribunal competente, tiene la potestad de disponer el rechazo de la acción sin sustanciarla por ser manifiestamente improcedente (SCHIAVI, 2014).

En anteriores oportunidades hemos señalado que una de las principales innovaciones de la Ley, es la consagración de un procedimiento administrativo especial para acceder a la información pública. Vale recordar que los sujetos obligados son tanto personas públicas estatales como no estatales que no tienen un procedimiento administrativo común que rija las actuaciones propias de 
cada una de ellas. Por lo que, en materia de acceso a la información pública, la ley en forma expresa viene a establecer un procedimiento administrativo especial, común a ambas.

En cuanto al procedimiento administrativo especial en materia de acceso a la información pública, simplemente recordar que se regulan expresamente: la solicitud de acceso a la información pública y sus requisitos (artículo 13); los límites del acceso a la información pública (artículo 14.); los plazos (artículo 15); la competencia para decidir (artículo 16); el acceso (artículo 17), y el silencio positivo (artículo 18), remitiéndonos al trabajo referido (SCHIAVI, 2014).

\section{HABEAS DATA IMPROPIO: ACCIÓN DE ACCESO A LA INFORMACIÓN PÚBLICA}

\subsection{Generalidades}

El derecho a la protección de datos personales y al acceso a la información pública son derechos distintos pero relacionados. Tienen en común el hecho de que ambos derivan del derecho a la información, derecho que a su vez deriva del derecho a averiguar la verdad que proviene de la naturaleza específica de ser racional del hombre (DURÁN MARTíNEZ, 2012, p. 7).

Por esa misma razón el instrumento jurisdiccional de protección de ambos derechos suele llevar la misma denominación: HÁBEAS DATA. Se habla de hábeas data propio y hábeas data impropio. En Uruguay son objeto de una regulación prácticamente igual con las Leyes $N^{\circ} 18.331$ de 11 de agosto de 2008 (arts. 37 y siguientes), y No 18.381, de 17 de octubre de 2008 (arts. 22 y siguientes) (DURÁN MARTíNEZ, 2012, p. 7).

La Ley No 18.381, dedica el Capítulo V - Arts. 22 a 30- al hábeas data impropio, pero no recoge esa denominación. Por parte su artículo 22 llama a esta acción: acción de acceso a la información pública (DURÁN MARTÍNEZ, 2012, p. 159).

A texto expreso dispone el artículo 22 de la Ley, que toda persona tendrá derecho a entablar una acción judicial efectiva que garantice el pleno acceso a las informaciones de su interés (artículo 694 de la Ley № 16.736 , de 5 de enero de $1996^{1}$ ).

Se tratan de procesos que revisten a su vez, el carácter principal y autónomo. Son procesos constitucionales aquellos previstos expresamente por la Constitución. Pero también se consideran procesos constitucionales aquellos "especialmente destinados a tutelar principios, valores o derechos constitucionales". Dentro de esta perspectiva no cabe duda que en Uruguay el hábeas data impropio es un proceso constitucional (DURÁN MARTíNEZ, 2012, p. 165).

\subsection{Procedencia}

El hábeas data impropio procede cuando el organismo público que ha recibido una solicitud de acceso a la información la ha rechazado o no se expidió en los plazos legales (DURÁN MARTÍNEZ, 2012, p. 161).

\footnotetext{
${ }^{1}$ Artículo 694.- "Las administraciones públicas impulsarán el empleo y aplicación de medios informáticos y telemáticos para el desarrollo de sus actividades y el ejercicio de sus competencias, garantizando a los administrados el pleno acceso a las informaciones de su interés".
}

Revista do Direito [ISSN 1982-9957]. Santa Cruz do Sul, v. 2, n. 49, p. 70-95, maio/ago. 2016. https://online.unisc.br/seer/index.php/direito/index 
Al respecto el artículo 23 dispone: "la acción de acceso a la información procede contra todo sujeto obligado por la presente ley, cuando éste se negare a expedir la información solicitada o no se expidiese en los plazos fijados en la presente ley".

En lo que refiere al tema que estamos analizando, es importante recordar lo dispuesto por la Ley en lo relativo a los plazos, competencia para decidir y acceso (artículos 16, 17 y 18) (SCHIAVI, 2014, p. 410).

Cualquier persona física o jurídica podrá formular la petición de acceso a la información en poder de los sujetos obligados. Ante la petición formulada por el interesado, el organismo requerido está obligado a permitir el acceso o, si es posible, contestar la consulta en el momento en que sea solicitado (lo cual en los hechos es imposible de que pueda suceder).

En caso contrario tendrá un plazo máximo de veinte días hábiles para permitir o negar el acceso o contestar la consulta. El plazo podrá prorrogarse, con razones fundadas y por escrito, por otros veinte días hábiles si median circunstancias excepcionales.

En la práctica ha acontecido que, ante la presentación de una solicitud de acceso a la información pública ante un sujeto obligado, éste en forma previa a pronunciarse sobre el mismo, efectúa una consulta ante el órgano de control, esto es, la Unidad de Acceso a la Información Pública (UAIP). Entendemos que dicha consulta y la eventual evacuación de la misma por la UIAP, a los efectos del cómputo de los plazos para el sujeto obligado, deben efectuarse dentro de los plazos legales, y que la no evacuación de la misma, o su evacuación extemporánea, no constituyen motivo fundado para no pronunciarse sobre la solicitud en los plazos correspondientes (SCHIAVI, 2014, p. 410).

La regla, en materia de acceso a la información pública es, valga la redundancia, permitir el acceso y, si es posible, en el mismo momento. De acuerdo a la ley que estamos analizando, la solicitud de acceso debe dirigirse al Jerarca máximo de cada organismo, quien tiene la competencia para decidir respecto de la misma en cuanto a su trámite.

El acto que resuelva sobre la petición deberá emanar del jerarca máximo del organismo o quien ejerza facultades delegadas y deberá franquear o negar el acceso a la información que obrare en su poder relativa a la solicitud en forma fundada.

Esto es, por acto administrativo, el Jerarca o quien ejerza su competencia, deberá pronunciarse en forma fundada respecto de la solicitud de acceso, haciendo lugar o negando el acceso a la información solicitada.

En caso de que no se haga lugar a la solicitud de acceso, la motivación del acto administrativo denegatorio es restringida y limitada al carácter reservado o confidencial de la información.

El organismo requerido sólo podrá negar la expedición de la información solicitada mediante resolución motivada del jerarca del organismo que señale su carácter reservado o confidencial, indicando las disposiciones legales en que se funde.

Aunque la Ley aquí no menciona los casos de informaciones secretas, es obvio que también aquí corresponde el rechazo de la solicitud pues es una de las excepciones previstas en el artículo 8 de la metada Ley.

Por último, se incluyen los casos en los cuales la denegación de la solicitud se debe a la inexistencia de datos en su poder, respecto de la información solicitada.

Revista do Direito [ISSN 1982-9957]. Santa Cruz do Sul, v. 2, n. 49, p. 70-95, maio/ago. 2016. https://online.unisc.br/seer/index.php/direito/index 
Como se percibe, esta solicitud de acceso formulada extrajudicialmente es requisito de admisibilidad de la acción en análisis (DURÁN MARTíNEZ, 2012, p. 161).

Vencido el plazo de veinte días hábiles desde la presentación de la solicitud, si no ha mediado prórroga o vencida la misma sin que exista resolución expresa notificada al interesado, éste podrá acceder a la información respectiva, considerándose falta grave la negativa de cualquier funcionario a proveérsela, de conformidad con las previsiones de la Ley № 17.060, de 23 de diciembre de 1998, y del artículo 31 de la presente ley.

\subsection{Competencia}

En cuanto a la competencia, se dispone que serán competentes para conocer en estas acciones:

1. En la capital, los Juzgados Letrados de Primera Instancia en lo Contencioso Administrativo, cuando la acción se dirija contra una persona pública estatal, y los Juzgados Letrados de Primera Instancia en lo Civil en los restantes casos.

2. En el interior, los Juzgados Letrados de Primera Instancia a los que se haya asignado competencia en la materia.

Si bien la Ley iguala en cuanto a sus deberes y obligaciones a las personas públicas estatales y no estatales, consagra una diferencia en cuanto a los Juzgados competentes en la capital para pronunciarse respecto de la acción de acceso a la información pública, según la acción se dirija contra una persona pública estatal o no estatal (SCHIAVI, 2012, p. 68).

Cabe destacar la Sentencia del Juzgado Letrado de Primera Instancia en lo Contencioso Administrativo de $1^{\circ}$ Turno, de 2 de setiembre de 2013, en autos caratulados "COPSA C/ CND.Acción de Acceso a la Información Pública", donde la Sede hace lugar a la excepción de incompetencia interpuesta por la CND ya que los Juzgados Letrados de Primera Instancia en lo Contencioso Administrativo son incompetentes al tratarse de un persona de derecho público no estatal.

\subsection{Legitimación}

La legitimación activa para promover el hábeas data impropio es más amplia que en el caso del hábeas data propio. En este caso se limita al titular de los datos por sí o a través de sus representantes (DURÁN MARTíNEZ, 2012, p. 160).

La acción de acceso a la información podrá ser ejercida por el sujeto interesado o sus representantes, ya sean tutores o curadores y, en caso de personas fallecidas, por sus sucesores universales, en línea directa o colateral hasta el segundo grado, por sí o por medio de apoderado.

En el caso de personas jurídicas, la acción deberá ser interpuesta por sus representantes legales o por los apoderados designados a tales efectos.

En este caso, basta con un interés simple, ya que la Ley no exige un interés especial; simplemente dice "sujeto interesado". Esta solución es coherente con la de los artículos 3 y 13 de la Ley que asignan el derecho a acceder a la información y a solicitarla en vía administrativa 
respectivamente a cualquier persona sin especificar una situación jurídica subjetiva en particular (DURÁN MARTÍNEZ, 2012, p. 160).

\subsection{Procedimiento de primera instancia}

Las acciones que se promuevan por violación a los derechos contemplados en la Ley se regirán por las normas contenidas en los artículos que siguen al presente.

Serán aplicables en lo pertinente los artículos $14^{2}$ y $15^{3}$ del Código General del Proceso.

Esta remisión expresa a los criterios de interpretación e integración del C.G.P hace que se amplíe el elenco de normas procesales que pueden ser utilizadas en este proceso (DURÁN MARTÍNEZ, 2012, p. 161/162).

En cuanto a la primera instancia, se dispone expresamente que salvo que la acción fuera manifiestamente improcedente ${ }^{4}$, en cuyo caso el tribunal la rechazará sin sustanciarla y dispondrá el archivo de las actuaciones, se convocará a las partes a una audiencia pública dentro del plazo de tres días de la fecha de la presentación de la demanda.

En dicha audiencia se oirán las explicaciones del demandado, se recibirán las pruebas y se producirán los alegatos. El tribunal, que podrá rechazar las pruebas manifiestamente impertinentes o innecesarias, presidirá la audiencia so pena de nulidad, e interrogará a los testigos y a las partes, sin perjuicio de que aquéllos sean, a su vez, repreguntados por los abogados. Gozará de los más amplios poderes de policía y de dirección de la audiencia.

En cualquier momento podrá ordenar diligencias para mejor proveer.

La sentencia se dictará en la audiencia o a más tardar, dentro de las veinticuatro horas de su celebración. Sólo en casos excepcionales podrá prorrogarse la audiencia por hasta tres días.

Las notificaciones podrán realizarse por intermedio de la autoridad policial. A los efectos del cómputo de los plazos de cumplimiento de lo ordenado por la sentencia, se dejará constancia de la hora en que se efectuó la notificación.

Si de la demanda o en cualquier otro momento del proceso resultare, a juicio del tribunal, la necesidad de su inmediata actuación, éste dispondrá, con carácter provisional, las medidas que correspondieren en amparo del derecho o libertad presuntamente violados.

\subsection{La sentencia}

\footnotetext{
${ }^{2}$ Código General del Proceso, artículo 14. “Interpretación de las normas procesales.- Para interpretar la norma procesal, el tribunal deberá tener en cuenta que el fin del proceso es la efectividad de los derechos sustanciales. En caso de duda se deberá recurrir a las normas generales teniendo presente los principios generales de derecho y especiales del proceso y la necesidad de preservar las garantías constitucionales del debido proceso y de la defensa en el mismo".

${ }^{3}$ Código General del Proceso, artículo 15. “Integración de las normas procesales.- En caso de vacío legal, se deberá recurrir a los fundamentos de las leyes que rigen situaciones análogas y a los principios constitucionales y generales de derecho y especiales del proceso y a las doctrinas más recibidas, atendidas las circunstancias del caso".

${ }^{4}$ El tribunal tiene la potestad de disponer el rechazo de la acción sin sustanciarla en caso de que sea manifiestamente improcedente. Se trataría del caso de que se concurra a la sede judicial sin haberse agotado previamente el procedimiento administrativo de acceso a la información pública.
} 
La sentencia que haga lugar a la acción de acceso deberá contener:

A. La identificación concreta de la autoridad o el particular a quien se dirija y contra cuya acción, hecho u omisión se garantice el acceso.

B. La determinación precisa de lo que deba o no deba hacerse y el plazo por el cual dicha resolución regirá, si es que corresponde fijarlo.

C. El plazo para el cumplimiento de lo dispuesto, que será fijado por el tribunal conforme las circunstancias de cada caso, y no será mayor de quince días corridos e ininterrumpidos, computados a partir de la notificación.

\subsection{Procedimiento de segunda instancia}

En el proceso sólo serán apelables la sentencia definitiva y la que rechaza la acción por ser manifiestamente improcedente.

El recurso de apelación deberá interponerse en escrito fundado, dentro del plazo perentorio de tres días. El tribunal elevará sin más trámite los autos al superior cuando hubiere desestimado la acción por improcedencia manifiesta, y lo sustanciará con un traslado a la contraparte, por tres días perentorios, cuando la sentencia apelada fuese la definitiva.

El tribunal de alzada resolverá en acuerdo, dentro de los cuatro días siguientes a la recepción de los autos. La interposición del recurso no suspenderá las medidas de amparo decretadas, las cuales serán cumplidas inmediatamente después de notificada la sentencia, sin necesidad de tener que esperar el transcurso del plazo para su impugnación.

En este tipo de procesos no podrán deducirse cuestiones previas, reconvenciones ni incidentes.

El tribunal, a petición de parte o de oficio, subsanará los vicios de procedimiento, asegurando, dentro de la naturaleza sumaria del proceso, la vigencia del principio contradictorio.

Cuando se planteare la inconstitucionalidad por vía de excepción o de oficio (numeral 2 del artículo $509^{5}$ y numeral 2 del artículo $510^{6}$ del Código General del Proceso) se procederá a la suspensión del procedimiento sólo después que el Magistrado actuante haya dispuesto la adopción de las medidas provisorias referidas en la presente ley o, en su caso, dejando constancia circunstanciada de las razones de considerarlas innecesarias.

\footnotetext{
${ }^{5}$ Código General del Proceso, artículo 509. Titulares de la solicitud. La declaración de inconstitucionalidad y la inaplicabilidad de las disposiciones afectadas por aquélla, podrán ser solicitadas:

$1^{\circ}$ Por todo aquél que se considere lesionado en su interés directo, personal y legítimo.

$2^{\circ}$ De oficio, por el tribunal que entendiere en cualquier procedimiento jurisdiccional.

La Suprema Corte de Justicia, en los asuntos que se tramiten ante ellas, se pronunciará en la sentencia sobre la cuestión de inconstitucionalidad.

${ }^{6}$ Código General del Proceso, artículo 510. Acción o excepción. Cuando la declaración de inconstitucionalidad se solicitare por las personas a que se refiere el numeral $1^{\circ}$ del artículo anterior podrá ser promovida:

$1^{\circ}$ Por vía de acción, cuando no existiere procedimiento jurisdiccional pendiente. En este caso, deberá interponerse directamente ante la Suprema Corte de Justicia.

$2^{\circ}$ Por vía de excepción o defensa, que deberá oponerse ante el tribunal que estuviere conociendo en dicho procedimiento.
}

Revista do Direito [ISSN 1982-9957]. Santa Cruz do Sul, v. 2, n. 49, p. 70-95, maio/ago. 2016. https://online.unisc.br/seer/index.php/direito/index 


\section{5. ¿ACCIÓN DE ACCESO A LA INFORMACIÓN PÚBLICA INCONSTITUCIONAL?: SENTENCIA DE LA SUPREMA CORTE DE JUSTICIA N 185/013 DE 13 DE MARZO DE 2013.}

Por Sentencia N 185/013 de 13 de marzo de 2013, la Suprema Corte de Justicia (SCJ) se pronunció sobre la constitucionalidad de la ley de acceso a la información pública, y, especialmente sobre la regulación jurídica de la acción de acceso a la información pública, hábeas data impropio.

En el caso a estudio vale señalar que se presentaron varias empresas de televisión para abonados que operan en las localidades de Canelones, Pando, Colonia, Santa Lucía, San Carlos, Chuy, Tala, Rivera, Melo, Treinta y Tres, Young y Guichón, promoviendo por vía de acción, la declaración de inconstitucionalidad de lo dispuesto en los arts. 2, 4, 13 a 18 y 25 a 31 de la Ley No. 18.381.

En este punto debemos recordar que por Sentencia No. 144/2011, dictada por el Juzgado Letrado de Primera Instancia en lo Contencioso Administrativo de 1er. Turno, en autos caratulados "Asociación de la Prensa Uruguaya C/ URSEC Unidad Reguladora de Servicios de Comunicaciones Amparo", se condenó a la demandada a brindar a los actores la información relativa a la cantidad de abonados a la televisión por cable de las localidades referidas, en un plazo de 15 días. El fallo referido recayó en proceso de amparo promovido en base a la Ley No. 18.381, en la que se regula el Derecho de Acceso a la Información Pública.

En relación a los arts. 25 a 31 de la Ley No. 18.381, los accionantes expresaron que "Al igual que en el caso del procedimiento administrativo, los arts. 25 a 30 (que regulan el reclamo a nivel jurisdiccional), son inconstitucionales porque no prevén el emplazamiento a los particulares cuando se trata de datos personales en poder de organismos públicos. Mientras que cuando se trata de información pública (en su correcta acepción), los principios que rigen el litigio son los de publicidad y transparencia, cuando se trata de datos personales los principios son los contrarios y están protegidos por normas de rango constitucional (art. 1 de la Ley No. 18.381, citando el art. 72 de la Constitución). El particular eventualmente afectado tiene derecho a que se le convoque y pueda reclamar la consideración, por el tribunal, de los principios y reglas que protegen su información. El debido proceso está recogido directamente en los arts. 12, 18 y 66 de la Carta, pero a través del art. 72 pasa a estar protegido también por las Convenciones de Derechos Humanos que refieren al debido proceso legal, ratificadas por Uruguay, que pasan así a tener rango constitucional. Los arts. 22 a 31 de la Ley No. 18.381 son inconstitucionales por violar los arts. 12, 18 y 66 de la carta y, a través del art. 72, los arts. 8 y 10 de la Declaración Universal de Derechos Humanos, y el art. 8 del Pacto de San José de Costa Rica. La inconstitucionalidad resulta tan evidente, que el legislador terminó el capítulo correspondiente previendo la existencia de acciones de inconstitucionalidad (art. 31 inc. 2 de la Ley No. 18.381). En definitiva, solicitan que previo cumplimiento de las ritualidades procesales correspondientes, se declare inconstitucional los artículos de la Ley No. 18.381 antes mencionados".

Como puede apreciarse en esta acción de declaración de inconstitucionalidad queda de manifiesto el conflicto entre derechos fundamentales y la permanente tensión que puede plantearse, 
como en este caso, entre el derecho de acceso a la información pública y el derecho a la protección de datos personales.

Pero éste no es el punto de nuestro análisis. Lo que aquí se plantea es fruto de la no previsión a texto expreso en el articulado del emplazamiento a los particulares cuando se trata de datos personales en poder de organismos públicos.

Los accionantes lo sintetizan, valga la redundancia, al expresar que "...son inconstitucionales porque no prevén el emplazamiento a los particulares cuando se trata de datos personales en poder de organismos públicos. Mientras que cuando se trata de información pública (en su correcta acepción), los principios que rigen el litigio son los de publicidad y transparencia, cuando se trata de datos personales los principios son los contrarios y están protegidos por normas de rango constitucional (art. 1 de la Ley No. 18.381, citando el art. 72 de la Constitución). El particular eventualmente afectado tiene derecho a que se le convoque y pueda reclamar la consideración, por el tribunal, de los principios y reglas que protegen su información..."

Y sobre este asunto en particular debe reconocerse lo ya señalado de que no está estipulada a texto expreso la vista a los particulares terceros titulares de la información (SCHIAVI, 2014, p. 410).

Aunque por aplicación de los principios generales del debido proceso administrativo (Arts. 12, 18 y 66 de la Carta, Decreto 500/991) perfectamente el organismo público que reciba la solicitud podría dar vista al tercero en caso de corresponder.

La Corporación, por unanimidad de sus integrantes naturales, desestimó la acción de declaración de inconstitucionalidad promovida al entender que "La propia Ley No. 18.331, sobre Protección de Datos Personales, contiene disposiciones que habilitan la comunicación de datos sin intervención de su titular, cuando la Ley de interés general así lo dispone (art. 17), o se recaben en función de una "obligación legal" (art. 9). El llamado principio de consentimiento no es absoluto y reconoce excepciones a texto expreso".

"En el caso, hay una Ley de interés general como lo es la Ley sobre Acceso a Información Pública, y existe un marco legal que impone deberes a empresas como las accionantes. La actividad de las empresas de cable es una actividad privada de interés público (cfme: Delpiazzo, Carlos, "Régimen jurídico de la TV para abonados en Uruguay", Prisma No. 2, UCUDAL, pág. 94; Cagnoni, José Aníbal y Frugone Schiavone, Héctor, en consultas publicadas en Revista Uruguaya de Derecho Constitucional y Político, 1994, págs.. 464 y 527-528 respectivamente). Tal naturaleza de la actividad desarrollada por las accionantes conlleva un grado de contralor y publicidad relevantes, precisamente por el interés público en juego. Por tal motivo, los operadores de cable se encuentran sometidos a un estricto contralor por la URSEC, conforme lo dispuesto por la Ley No. 17.296 (arts. 70 y ss.), en el marco del cual deben informar la cantidad de abonados".

"Por otra parte, el número de abonados de una empresa de televisión por cable que obra en un registro de la autoridad reguladora, no califica ni como "dato sensible", de acuerdo con la Ley No. 18.331, ni como dato "reservado" o "confidencial", conforme lo dispuesto por la Ley No. 18.381".

En el punto esencial que nos interesa, la SCJ no se pronuncia sobre el fondo del asunto, al estimar que "en la medida que, los artículos cuya declaración de inconstitucionalidad se impetra, 
refieren al procedimiento administrativo para acceder a la información pública (arts. 13 a 18), y a la acción e acceso a la información (arts. 25 a 31), y no acreditando los actores haber iniciado procedimiento administrativo o jurisdiccional de los regulados en dichas normas, carecen de legitimación activa, al no ser titulares del interés requerido para la declaración pretendida". En primer lugar, en cuanto al tema relativo a la legitimación activa, cabe tener presente que el art. 258 de la Carta y 509 del C.G.P., precisan quiénes pueden ser titulares de la solicitud al establecer que: "La declaración de inconstitucionalidad de una Ley y la inaplicabilidad de las disposiciones afectadas por aquélla, podrán solicitarse por todo aquel que se considere lesionado en su interés directo, personal y legítimo". Teniendo en cuenta los conceptos que vienen de señalarse, y dado que los accionantes no alegaron ni acreditaron ser parte de un procedimiento administrativo o jurisdiccional, regulado por las normas cuya declaración de inconstitucionalidad solicitan, la sola alegación de ser empresas de televisión para abonados, no traduce que las normas impugnadas les afecte en su interés directo, ni que estas le sean aplicadas en el futuro de forma inequívoca. Por consiguiente, en la medida en que los accionantes no acreditaron tener un interés directo lesionado sobre el punto, como se requiere a efectos de solicitar la declaración de inconstitucionalidad, corresponde rechazar la acción planteada".

Por tales fundamentos, la Suprema Corte de Justicia, por unanimidad, desestimó la acción de declaración de inconstitucionalidad deducida.

Nos hubiera gustado conocer la opinión de la Suprema Corte de Justicia sobre el fondo de lo planteado en cuanto a la inconstitucionalidad esgrimida de la acción de acceso a la información pública.

Sí entendemos que debería regularse a texto expreso en la Ley la puesta en conocimiento de los terceros titulares de la información en aplicación de los principios generales del debido procedimiento administrativo.

Hasta tanto eso no ocurra, ante una solicitud de acceso a la información promovida por un particular, y en el caso que dicha información esté en poder del Estado pero pertenezca a un tercero, el organismo público debería ponerlo en conocimiento del mismo previo a pronunciarse sobre la petición.

Aunque después habrá que discutir que acontece si el tercero titular de la información se opone al acceso de la misma.

Sobre el punto la Suprema Corte de Justicia (SCJ) ha manifestado que la ley no 18.831 de acceso a la información pública ha salvado su primer test de constitucionalidad, según palabras del Ministro de la Suprema Corte de Justicia Dr. Ricardo Pérez Manrique en una disertación que ofreció en el marco del II Seminario Internacional de Acceso a la Información Pública realizado el 10 de abril y organizado por AGESIC: "la Ley ha salvado un primer test de constitucionalidad y en el mismo año un Tribunal Civil ha aplicado la ley conforme a sus objetivos y principios, es decir el predominio del acceso público a la información frente a los intereses de particulares o de la propia organización estatal...". 


\section{CASO PRÁCTICO EL PAÍS C/ ADMINISTRACIÓN NACIONAL DE EDUCACIÓN PÚBLICA (ANEP): DATOS DEL MONITOR EDUCATIVO DE PRIMARIA Y SECUNDARIA COMO INFORMACIÓN PÚBLICA}

En este Capítulo haremos referencia al primer "leading case" en sede de información pública en nuestro país, que tuvo amplia repercusión a lo largo del año 2013 en todos los medios de comunicación y en la opinión pública.

El proceso se inició en marzo de 2013 con el pedido del Suplemento Qué Pasa de El País (http://www.elpais.com.uy/informacion/justicia-rechazo-apelacion-anep-obliga.html), de acceder a los datos de los indicadores del monitor educativo de Primaria y de Secundaria. La solicitud inicial requería acceder a las cifras discriminadas por escuelas y liceos, bajo el amparo de la ley 18.381, de Acceso a la Información Pública.

Esto es, un medio de prensa se presenta ante la Administración Nacional de Educación Pública (ANEP) para acceder la información de los monitores educativos de Primaria y Secundaria a través del procedimiento administrativo especial previsto en la Ley.

A principios de julio de 2013 la ANEP se pronuncia expresamente sobre la solicitud acogiendo parcialmente lo solicitado: esto es, permite acceder sólo a la información referida a Primaria.

Para acceder a los datos de Secundaria, el diario "El País" debió interponer la acción de acceso a la información pública ante la Justicia Competente en la medida que la ANEP no permitió el acceso a la información de secundaria esgrimiendo que "las cifras de Ciclo Básico eran reservadas y que no tenía las de Bachillerato".

El juez del caso en primera instancia, Dr. Pablo Eguren, pidió conocer, "aunque sea, datos genéricos de los resultados en Bachillerato y, al final, aparecieron las cifras de matrícula, alumnos aprobados y repetidores del último ciclo liceal".

La negativa de la ANEP tenía como fundamento central que los datos solicitados "podían generar "discriminación o estigmatización" de los centros educativos".

Sin embargo, el juez Eguren entendió que los argumentos planteados por la ANEP "no eran correctos y obligó al principal órgano de la educación a difundir los datos. El organismo no se dio por satisfecho con tal respuesta y por lo tanto apeló la sentencia, aunque de nuevo obtuvo un fallo contrario".

Lo interesante de este proceso fue que tuvieron lugar, todas y cada una de las instancias procedimentales previstas en la Ley, ya que la ANEP apeló la sentencia del Dr. Pablo Eguren y la decisión final sobre el asunto recayó en segunda instancia en Tribunal de Apelaciones en lo Civil de 1er Turno (http://www.elpais.com.uy/informacion/anep-se-nego-nuevo-brindar.html).

El Tribunal de Apelaciones en lo Civil de 1er Turno se expidió en contra de la ANEP, y "en un fallo por demás contundente obligó a dar los datos. A la misma vez, defendió la importancia del acceso a la información pública"( http://www.elpais.com.uy/informacion/justicia-rechazo-apelacionanep-obliga.html).

La respuesta del Tribunal comienza recordando que la ANEP planteó que la ley le impide dar la información requerida para evitar cualquier forma de "estigmatización y discriminación de 
estudiantes, docentes o instituciones", y también dijo que "no se trata de información reservada ni confidencial sino que hay un claro impedimento legal para proporcionarla" (http://brecha.com.uy/index.php/politica-uruguaya/2794-golpe-a-una-cultura-institucional).

Sin embargo, contesta que "la Sala no comparte el enfoque de la apelante (ANEP) y habrá de confirmar la recurrida por diferentes razones". Así, pasa a explicar que no es válido señalar en este caso que el hecho de que la información pueda generar discriminación, represente una excepción frente al derecho a la información.

El Tribunal dijo no entender que se establezca esa excepción porque, en primer lugar, las excepciones a la información pública "son de interpretación estricta y comprenden aquellas que la ley define como secretas o exceptuadas, lo cual no es el caso" de lo planteado por la ley específica de protección de datos en el área de la educación.

El fallo afirma que el primer error en el que se incurre es "extraer de una directiva dirigida al Instituto Nacional de Evaluación Educativa una pretendida excepción al derecho de acceso a la información".

También señala: "No puede soslayarse que no se ha demostrado que la difusión pública de la información que se pide responda al propósito o tenga necesariamente el efecto que le atribuye la apelante".

"El conocimiento de la cantidad de estudiantes de cada liceo y las cantidades o porcentajes de aprobados y de reprobados carece de aptitud para provocar discriminación o estigmatización", dice el fallo. Además añade que para que eso ocurra "no basta dar información que es oficial y se supone es objetiva y veraz".

En la misma línea, se afirma que "no hay elementos para presumir que la información se pida con ese propósito, ni puede negarse información que es pública. (...) Tampoco puede afirmarse con la certeza necesaria que esa información va a perjudicar injustificadamente a ciertos liceos, como sostiene la apelante", expresa el texto.

Es muy importante destacar asimismo en el fallo del Tribunal de Apelaciones las consideraciones efectuadas sobre la libertad de prensa y el derecho a la información, pilares fundamentales del derecho de acceso a la información pública a los cuales hemos hecho referencia al inicio del presente trabajo (http://www.espectador.com/sociedad/236799/anep-instada-a-publicarcuales-escuelas-tienen-habilitacion)

La sentencia realiza una extensa defensa del derecho a acceder a la información pública y también destaca el papel que cumplen los medios de comunicación al establecer que "La posibilidad de que el periodista o el medio de comunicación hagan un uso indebido de la información, no habilita a las autoridades requeridas a negarse a informar", dice el fallo, que también expresa que el derecho a la información pública "no requiere justificar las razones por las que se solicita".

"No puede olvidarse que el derecho de acceder a la información pública y de informar públicamente es uno de los derechos fundamentales más importantes para un Estado republicano, democrático y de derecho, por lo que tiene rango constitucional", expresó el Tribunal de Apelaciones. El fallo recuerda que la Suprema Corte de Justicia "tiene dicho" que "tanto el derecho a la información como la libertad de prensa son derechos tan trascendentes que pueden ser ubicados en un plano 
superior al de otros derechos civiles pues de ello depende la estructura de las relaciones entre el poder y la libertad".

De acuerdo al Diario El Observador, "con los datos conseguidos hasta ahora, se supo cuáles son los resultados de las escuelas de Montevideo, además del promedio de repetición en Bachillerato, que en la capital fue de $52 \%$ y en todo el país $44 \%$. También que en 6 to de liceo repite casi el $60 \%$ y 6.841 alumnos terminaron segundo ciclo en $2012 "$.

Pequeñas reflexiones sobre el caso a estudio. En primer lugar, me pregunto: ¿Si los datos de los indicadores del monitor educativo de Primaria y de Secundaria de la ANEP no son información pública?: ¿qué es información pública? En segundo lugar, debe destacarse que fue el primer caso en nuestro país donde se cumplieron todas las instancias procedimentales previstas en la Ley. Y por último, quedaron de manifiesto las dificultades para acceder a información pública en determinadas reparticiones oficiales.

Al finalizar este trabajo tomamos conocimiento que "la Administración Nacional de Educación Pública (ANEP) trabaja en un cambio de política respecto a la divulgación de los indicadores educativos (asistencia, repetición, abandono) de los distintos subsistemas (Primaria, Secundaria y UTU), informaron a El Observador fuentes del organismo. El Consejo de Educación Inicial y Primaria (CEIP) presentó ayer la nueva página de su Monitor Educativo, plataforma donde cualquier ciudadano puede acceder a estos datos y tendencias, desde el año 2002, discriminados por centros educativos. En la presentación, el director general de Primaria, Héctor Florit manifestó que el cambio de política se debió a un fallo judicial del año pasado que había obligado a la ANEP a hacer públicos estos datos” (http://www.elobservador.com.uy/noticia/285157/-anep-cambia-politica-y-publicara-datoseducativos-por-centros/).

Hasta el 2013, la ciudadanía no tenía acceso a estos datos discriminados por centros educativos. Sin embargo, el fallo judicial al cual hemos hecho referencia -a raíz de un pedido de acceso a la información promovido por El País- sentó un precedente y en él se basan las autoridades hoy para comenzar a divulgar los indicadores educativos discriminados de acuerdo a cada centro, año tras año.

Cuadro Diario EI País C/ ANEP Información Pública

\begin{tabular}{|l|l|}
\hline Sujeto activo & $\begin{array}{l}\text { Suplemento Qué Pasa Diario El } \\
\text { País }\end{array}$ \\
\hline Sujeto Pasivo & $\begin{array}{l}\text { Administración Nacional de } \\
\text { Educación Pública (ANEP) }\end{array}$ \\
\hline Sitio Web & www.anep.edu.uy/ \\
\hline Descripción clara de & $\begin{array}{l}\text { Los datos de los indicadores del } \\
\text { monitor educativo de Primaria y } \\
\text { de Secundaria. La solicitud } \\
\text { inicial requería acceder a las } \\
\text { cifras discriminadas por } \\
\text { escuelas y liceos }\end{array}$ \\
\hline Transparencia Activa & $\begin{array}{l}\text { Al día de la solicitud no figuraba } \\
\text { lo solicitado en la Web de la } \\
\text { ANEP }\end{array}$ \\
\hline
\end{tabular}




\begin{tabular}{|c|c|}
\hline Transparencia Pasiva & $\begin{array}{l}\text { Corresponde presentar solicitud } \\
\text { de acceso a la información } \\
\text { pública }\end{array}$ \\
\hline Procedimiento Administrativo Especial & Ante la ANEP \\
\hline Competencia para decidir & ANEP \\
\hline Plazo para decidir & $\begin{array}{l}20 \text { días hábiles (más prorroga } \\
\text { en caso de proceder) }\end{array}$ \\
\hline Acto administrativo del sujeto obligado & $\begin{array}{l}\text { Permite acceso "parcial" a lo } \\
\text { solicitado: se limita sólo a "la } \\
\text { información de Primaria". La } \\
\text { ANEP primero dijo que las cifras } \\
\text { de Ciclo Básico eran reservadas } \\
\text { y que no tenía las de } \\
\text { Bachillerato. }\end{array}$ \\
\hline $\begin{array}{l}\text { Acción de acceso a la información } \\
\text { pública }\end{array}$ & Justicia competente \\
\hline $\begin{array}{l}\text { Procedimiento de primera instancia } \\
\text { /Sentencia: Juzgado Letrado de } \\
\text { Primera Instancia en lo Contencioso } \\
\text { Administrativo }\end{array}$ & $\begin{array}{l}\text { El juez del caso, Pablo Eguren, } \\
\text { pidió conocer, aunque sea, } \\
\text { datos genéricos de los } \\
\text { resultados en Bachillerato y, al } \\
\text { final, aparecieron las cifras de } \\
\text { matrícula, alumnos aprobados y } \\
\text { repetidores del último ciclo } \\
\text { liceal. Sin embargo, el juez } \\
\text { Eguren entendió que los } \\
\text { argumentos planteados por la } \\
\text { ANEP no eran correctos y obligó } \\
\text { al principal órgano de la } \\
\text { educación a difundir los datos. } \\
\text { El organismo no se dio por } \\
\text { satisfecho con tal respuesta y } \\
\text { por lo tanto apeló la sentencia, } \\
\text { aunque de nuevo obtuvo un } \\
\text { fallo contrario. }\end{array}$ \\
\hline $\begin{array}{lcr}\text { Procedimiento } & \text { de } & \text { segunda } \\
\text { instancia/Sentencia: } & \text { Tribunal de } \\
\text { Apelaciones en lo Civil de 1er Turno }\end{array}$ & $\begin{array}{l}\text { Se expidió en contra de la } \\
\text { ANEP, y en un fallo por demás } \\
\text { contundente obligó a dar los } \\
\text { datos. A la misma vez, defendió } \\
\text { la importancia del acceso a la } \\
\text { información pública y de la } \\
\text { libertad de prensa. }\end{array}$ \\
\hline
\end{tabular}

\section{CASO PRÁCTICO “ARATIRI”: DATOS DEL EXPEDIENTE RELATIVO A LA MINERA ARATIRI SOBRE EL PROYECTO VALENTINES DE EXTRACCIÓN Y BENEFICIAMIENTO DE MINERAL DE HIERRO COMO INFORMACIÓN PÚBLICA}

Vamos a hacer referencia en este capítulo a uno de los casos de acceso a la información pública que mayor repercusión pública ha tenido en los últimos meses en Uruguay. 
En esta oportunidad se presenta el Sr. Víctor Bachetta ante el Ministerio de Industria, Energía y Minería (MIEM) a los efectos de solicitar al amparo de la Ley de acceso a la información pública, la información contenida en el expediente relativa a los informes técnicos presentados por Minería Aratirí SA sobre el proyecto Valentines de Extracción y Beneficiamiento de Mineral de Hierro localizado en los Departamentos de Durazno, Florida, Treinta y Tres, Lavalleja y Rocha.

La solicitud se presentó ante el MIEM - DIRECCION NACIONAL DE MINERIA Y GEOLOGIA. Se formó expediente administrativo y con fecha 24/7/2014 la Asesoría Jurídica dictó informe en el que sugiere no acceder a lo solicitado fundado en la resolución de la Dirección Nacional de Minería y Geología Nro 122/2013 del 552013 por la cual se declara confidencial la totalidad de la información contenida en el expediente relativa a los informes técnicos presentados por Minería Aratirí SA.

La Dirección Nacional de Minería y Geología (MIEM) entiende que no se puede acceder a lo solicitado ya que por acto administrativo se declaró confidencial la totalidad de la información contenida en el expediente relativa a los informes técnicos presentados por Minería Aratirí SA.

De acuerdo con el art. 26 de la Ley $N^{\circ} 19.126$ en supuestos de proyectos de minería de gran porte la clasificación de información compete al MVOTMA o al MIEM, no es competencia de DINAMIGE declarar confidencial la información.

EI MIEM no ha contestado la solicitud realizada al amparo de la Ley $\mathrm{N}^{\circ} 18.381$, por lo tanto, ha operado "silencio positivo" establecido en el art. 18 de la Ley $N^{\circ} 18.381$ con las consecuencias jurídicas que la norma establece, esto es, en los hechos se ha agotado el procedimiento administrativo especial, razón por la cual, los interesados promueven la acción de acceso a la información pública ante la justicia competente.

En audiencia, los representantes del Ministerio de Industria, Energía y Minería (MIEM) declaran que en el expediente cuyo acceso se peticionaba existía la Resolución 122/13 del 1552013 por la que se declaraba confidencial la totalidad de la información contenida en el mismo y relativa a informes técnicos presentados por la Minera Aratirí SA.

Al respecto cabe recordar que oportunamente analizamos (SCHIAVI, 2014, p. 381) la correlación existente entre la № 19.126 de 11 de setiembre de 2013, regulatoria de la Minería de Gran Porte y la Ley $N^{\circ} 18.381$ de 17 de octubre de 2008, de Acceso a la Información Pública, teniendo presente la consagración de disposiciones relativas a la información confidencial y reservada en sede de los procedimientos de contratación para la celebración de contratos de explotación de minería de gran porte - entre otras disposiciones-, que suponen límites al acceso a la información pública.

El Artículo 26 de la Ley № 19.126 de 11 de setiembre de 2013 consagra previsiones especiales relativas a la información de carácter reservado o confidencial. Establece que "El titular del proyecto de Minería de Gran Porte podrá solicitar al Poder Ejecutivo, respecto a la información que ponga en conocimiento de este, la declaración de carácter reservado o confidencial, de acuerdo con lo dispuesto en el artículo 15 de la Ley $N^{\circ} 16.466$, de 19 de enero de 1994 , y en los artículos $8^{\circ}, 9^{\circ}$ y 10 de la Ley $N^{\circ}$ 18.381, de 17 de octubre de 2008. El Ministerio de Industria, Energía y Minería, en acuerdo con el Ministerio de Vivienda, Ordenamiento Territorial y Medio Ambiente, y en función de sus competencias respectivas, resolverá sobre la pertinencia de considerar dichos datos de carácter 
reservado o confidencial bajo resolución fundada. Aquellos datos que así se consideren se deberán presentar en documento separado. En ningún caso podrá ser considerada de carácter confidencial o reservada la información relacionada a los aspectos ambientales del proyecto".

Al respecto se dispone que el titular del proyecto de Minería de Gran Porte podrá solicitar al Poder Ejecutivo, respecto a la información que ponga en conocimiento de este, la declaración de carácter reservado o confidencial, de acuerdo con lo dispuesto en el artículo 15 de la Ley № 16.466 , de 19 de enero de 1994, y en los artículos $8^{\circ}, 9^{\circ}$ y 10 de la Ley $N^{\circ} 18.381$, de 17 de octubre de 2008 (SCHIAVI, 2014, P. 381).

El Ministerio de Industria, Energía y Minería, en acuerdo con el Ministerio de Vivienda, Ordenamiento Territorial y Medio Ambiente, y en función de sus competencias respectivas, resolverá sobre la pertinencia de considerar dichos datos de carácter reservado o confidencial bajo resolución fundada. Los ministerios competentes valorarán la reserva y/o confidencialidad solicitadas y deberá pronunciarse en forma fundada sobre si corresponde o no limitar del conocimiento público dicha información con la única excepción de que en ningún caso podrá ser considerada de carácter confidencial o reservada la información relacionada a los aspectos ambientales del proyecto. En consecuencia la información relacionada a los aspectos ambientales del proyecto siempre será pública y de acceso público no pudiendo ser objeto de resolución alguna que le otorgue carácter reservado y/o confidencial. Aquellos datos que se consideren reservados o confidenciales se deberán presentar en documento separado, lo cual sigue en líneas generales lo previsto en la Ley de Acceso a la Información Pública y decretos reglamentarios (SCHIAVI, 2014, P. 381).

En primera instancia, por Sentencia del Juzgado Letrado de Primera Instancia en lo Contencioso Administrativo de $2^{\circ}$ Turno de 10 de noviembre de 2014, se dispuso que corresponde en definitiva establecer la procedencia de la especial acción prevista en la ley 18.381 sobre acceso a la información pública disponiendo que el sujeto obligado brinde acceso al expediente Nro. 2904/2011 relativo a la Minera Aratirí sobre el Proyecto Valentines de Extracción y Beneficiamiento de Mineral de Hierro en el entendido de que "Indudablemente el acceso a la información pública es un derecho humano fundamental de expreso reconocimiento por la legislación nacional y por el sistema internacional de derechos humanos como se verá, que debe ser objeto de especial tutela cuando su limitación por razones excepcionales, no se encuentra debidamente justificada".

En Segunda Instancia, por Sentencia del Tribunal de Apelaciones en lo Civil de $4^{\circ}$ Turno de 5 de diciembre de 2014, se afirma que "El ordenamiento jurídico hace prevalecer el derecho a la información por sobre la morosidad de la Administración en pronunciarse. La configuración del silencio positivo no apareja la consecuencia automática del amparo del accionamiento promovido, porque como se ha sostenido "configurado el denominado silencio positivo, ello no autoriza sin más el amparo automático, por la sola constatación del vencimiento del plazo, en tanto el Tribunal llamado a intervenir, en ejercicio de su poder deber jurisdiccional, habrá de aplicar la normativa al caso concreto, determinando si se configuran los supuestos legales de la pretensión movilizada, en tanto es claro que no se trata de un mero homologador, máxime cuando la propia ley dispone en qué casos la información no ha de ser brindada". 
Pues bien, aplicando dicho proceso al caso de autos, se observa que, "frente al derecho de acceso a la información pública, se encuentra en juego el derecho de la empresa a la reserva de su información confidencial. Sin embargo, en la medida en que se ignora qué tipo de información es la resguardada mal puede continuarse con el examen, ya que ello debe ser realizado en base a las circunstancias de cada caso; circunstancias éstas que ser ignoran en virtud de la vaga fórmula empleada por la Administración al momento del dictado de la resolución 122/2013".

En consecuencia, el Tribunal de Apelaciones entiende que debe primar el principio general que garantiza el derecho fundamental de acceso a la información pública por sobre la pretendida excepción no justificada en el caso y confirmarse la recurrida en tanto hizo lugar la demanda.

\section{Cuadro Bachetta, Víctor C/ MIEM Información Pública}

\begin{tabular}{|l|l|}
\hline Sujeto activo & Víctor Bachetta \\
\hline Sujeto Pasivo & $\begin{array}{l}\text { Ministerio de Industria, Energía } \\
\text { y Minería (MIEM) }\end{array}$ \\
\hline Sitio Web & $\begin{array}{l}\text { Expediente 2904 Minera Aratirí } \\
\text { sobre el proyecto Valentines de } \\
\text { Extracción y Beneficiamiento de } \\
\text { Mineral de Hierro localizado en } \\
\text { la información requerida }\end{array}$ \\
\hline losepartamentos de Durazno, \\
Florida, Treinta y Tres, Lavalleja \\
y Rocha
\end{tabular}




\begin{tabular}{|c|c|}
\hline & $\begin{array}{l}\text { la información. Al día de la fecha } \\
\text { el MIEM no ha contestado la } \\
\text { solicitud realizada al amparo de } \\
\text { la Ley } 18.381 \text {, por lo tanto, ha } \\
\text { operado "silencio positivo" } \\
\text { establecido en el art. } 18 \text { de la } \\
\text { Ley } 18.381 \text {. }\end{array}$ \\
\hline $\begin{array}{l}\text { Acción de acceso a la información } \\
\text { pública }\end{array}$ & Justicia competente \\
\hline $\begin{array}{l}\text { Procedimiento de primera instancia } \\
\text { Sentencia: Juzgado Letrado de } \\
\text { Primera Instancia en lo Contencioso } \\
\text { Administrativo }\end{array}$ & $\begin{array}{l}\text { Indudablemente el acceso a la } \\
\text { información pública es un } \\
\text { derecho humano fundamental } \\
\text { de expreso reconocimiento por } \\
\text { la legislación nacional y por el } \\
\text { sistema internacional de } \\
\text { derechos humanos como se } \\
\text { verá, que debe ser objeto de } \\
\text { especial tutela cuando su } \\
\text { limitación por razones } \\
\text { excepcionales, no se encuentra } \\
\text { debidamente justificada }\end{array}$ \\
\hline 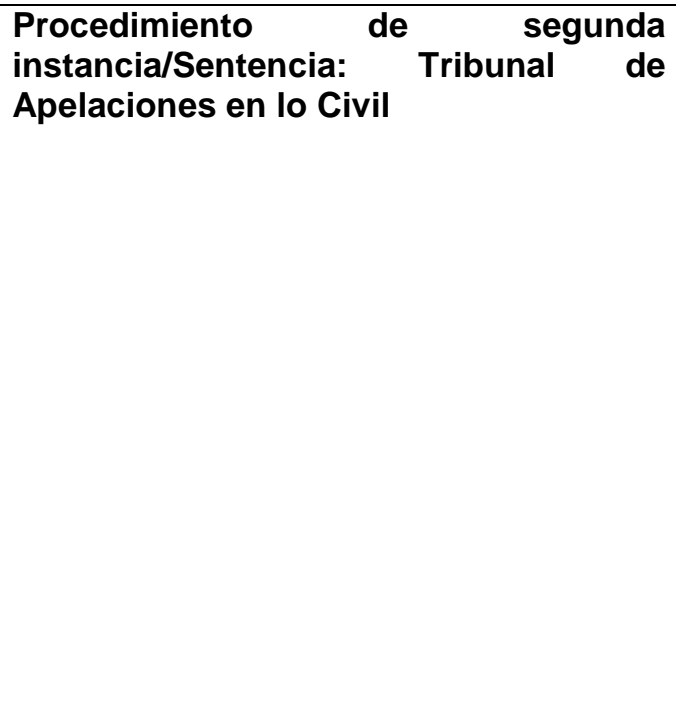 & $\begin{array}{l}\text { El ordenamiento jurídico hace } \\
\text { prevalecer el derecho a la } \\
\text { información por sobre la } \\
\text { morosidad de la Administración } \\
\text { en pronunciarse. } \\
\text { La configuración del silencio } \\
\text { positivo no apareja la } \\
\text { consecuencia automática del } \\
\text { amparo del accionamiento } \\
\text { promovido. } \\
\text { Debe primar el principio general } \\
\text { que garantiza el derecho } \\
\text { fundamental de acceso a la } \\
\text { información pública por sobre la } \\
\text { pretendida excepción no na el caso y } \\
\text { justificada en el a a recurrida en tanto } \\
\text { confirmarse la recanda. } \\
\text { hizo lugar la demanda. }\end{array}$ \\
\hline
\end{tabular}

\section{CASO PRÁCTICO "EL GUARDIÁN": INFORMACIÓN SOBRE EL NUEVO SISTEMA DE} VIGILANCIA E INTERCEPTACIÓN DE TELECOMUNICACIONES COMO INFORMACIÓN PÚBLICA

Con respecto a este caso, vamos a detenernos brevemente en la descripción de "El Guardián" para luego hacer referencia a los procedimientos administrativos y judiciales seguidos para acceder a la información relativa al mismo.

De acuerdo a informaciones difundidas en medios de prensa, el Ministerio del Interior y las empresas de telecomunicaciones comenzaron a realizar las primeras pruebas de funcionamiento de "El Guardián", el moderno equipo de espionaje que permitirá intervenir llamadas telefónicas y mails a través de la última tecnología. El sistema permite seguir en forma simultánea el tráfico de 800 celulares y 200 teléfonos fijos, y puede monitorear correos electrónicos y redes sociales (http://www.elobservador.com.uy/el-guardian-espiara-enero-mails-y-celulares-n289757). 
"La operación de compra debe mantenerse en secreto", sostiene la resolución presidencial que habilitó la adquisición por parte del Ministerio del Interior de compleja tecnología que dotará a las autoridades de una capacidad inexistente hasta el momento para sistematizar y analizar, al amparo de órdenes judiciales, la información surgida de la vigilancia de llamadas telefónicas, correos electrónicos, redes sociales y blogs (http://www.elpais.com.uy/informacion/gobierno-compro-guardianespiar-llamadas-correos.html).

Mientras en el mundo, a la luz del caso Snowden (el exagente que reveló espionaje ilegal del gobierno de los Estados Unidos), se debate la capacidad de los gobiernos para vigilar a sus ciudadanos en internet, el equipo comprado en Brasil y denominado El Guardián WEB, permite que al mismo tiempo 30 personas accedan a la vigilancia en tiempo real del tráfico que generan hasta 800 celulares y 200 teléfonos fijos. También habilita a crear cuentas espejo de hasta 100 suscripciones de e-mails y el monitoreo de hasta tres redes sociales (http://www.elpais.com.uy/informacion/gobiernocompro-guardian-espiar-llamadas-correos.html).

Con fecha 9 de marzo de 2015 se promovió una acción de acceso a la información pública contra el Ministerio del Interior sobre el nuevo sistema de vigilancia e interceptación de telecomunicaciones "El Guardián”, para saber la utilización del nuevo sistema y el conocimiento de las garantías que se prevén a efectos de resguardar el derecho a la privacidad de todas las personas.

En cuanto al procedimiento administrativo especial, simplemente cabe destacar que no se obtuvo respuesta, por lo que se configuró el silencio positivo dispuesto en el art. 18ำ de la ley $\mathrm{N}^{\circ}$ 18.381, razón por la cual se interpone la acción de acceso a la información pública.

Notificada la demanda y realizada la audiencia, el Ministerio del Interior contestó acerca de los presupuestos del accionamiento de la ley $\mathrm{N}^{\circ} 18.381$ y que en el caso no se dan, porque hizo referencia al art. $12^{\circ}$ porque la información solicitada está calificada como secreta y en el caso concreto como reservada.

Así lo entendió por el art. 33 del TOCAF y el Tribunal de Cuentas cuando aprobó sin observaciones el procedimiento de compra. Citó doctrina acerca del derecho a la seguridad y el art. $7^{\circ}$ de la Constitución, así como la ley 18.494 del año 2009 sobre la búsqueda de mejores tecnologías para el "control y prevención de lavado de activos y de financiamiento del terrorismo" y el art. 5우 que transcribió. Citó el Decreto N 452/2009 acerca de las políticas de seguridad. Entendió que no se configuró el silencio positivo, dado que ante la solicitud de la actora ante el Ministerio el decreto 500/91 exige conferir vista. Se confirió la vista, la que no fue evacuada por la actora.

La demandada ha probado, de acuerdo a la contestación de la demanda y la documentación que aportó consistente en la compra directa por excepción № 15/2013 amparada en el literal c del art. 33 numeral 8 del decreto 150/012 (TOCAF) que se vincula al art. 482 de la ley 15.903 en el literal H, así como en las resoluciones adoptadas por el Tribunal de Cuentas de 26/6/2013, que la operación de la compra directa por excepción № 15/2013 para el suministro de una solución GUARDIAO WEB para la interceptación de comunicaciones para la Secretaría de Estado en el resultando 1ํ "que la compra se ampara en el literal $\mathrm{C}$ del art. 33 numeral 8 del TOCAF, circunstancias que exigen que la operación deba mantenerse en secreto". El Tribunal aprobó el gasto sin observaciones. 
En Primera Instancia, por Sentencia del Juzgado Letrado de Primera Instancia en lo Contencioso Administrativo de $1^{\circ}$ Turno de 13 de marzo de 2015, se encuentra entonces que "la información solicitada por la accionante, se encuentra comprendida en los arts. 8ㅜ, 9ㅜㅗ $10^{\circ}$ de la ley 18.381. El "silencio positivo" no autoriza sin más al juez a disponer que se informe según lo pedido y la resolución administrativa denegatoria expresa que recayó más tarde, expresa que la información... es confidencial, por lo que de acuerdo al art. $10^{\circ}$ de la ley 18.381 se justifica la decisión denegatoria..." (TAC 1er. Turno). En este tipo de acciones debe de analizarse la licitud del pedido".

En Segunda Instancia, por Sentencia del TAC $5^{\circ}$ Turno de 21 de abril de 2015, se esgrime que "parece obvio que el secreto de la operación de adquisición del sistema operativo "guardián", avalado por el Tribunal de Cuentas, radica no solamente en la compra en sí misma (que, incidentalmente, no fue oculta) sino que también alcanza a las características técnicas del producto adquirido, por simples razones de seguridad y protección de los derechos de todos los habitantes que se busca tutelar mediante la prevención y represión de ilícitos, a través del empleo de instrumentos como el adquirido".

El Tribunal es conteste en señalar que "se trata de un instrumento para el combate del delito y la difusión pública de sus fortalezas y debilidades podría frustrar el empleo en esa tarea, dejándola librada a la actividad de "hackers" y/o personas que ilegítimamente pretendan obstaculizar o impedir investigaciones o represiones sometidas a control jurisdiccional, como bien expuso la parte demandada, con apoyo en normativa legal y administrativa específica (Decreto del PE 452/2009, resolución adjunta a la contestación de 30/7/2012 en asunto 7988/2012)".

A juicio del Tribunal, la sentencia apelada no vulnera el derecho al acceso a la información que postula la parte actora y por ello correctamente desestimó la demanda, lo cual determina la confirmatoria por la Sala.

Cuadro Da Rosa Pírez, Tania C/ Ministerio del Interior Información Pública

\begin{tabular}{|l|l|}
\hline Sujeto activo & Tania Da Rosa Pírez \\
\hline Sujeto Pasivo & Ministerio del Interior (MI) \\
\hline Sitio Web & www.minterior.gub.uy \\
\hline $\begin{array}{l}\text { Descripción clara de } \\
\text { la información requerida }\end{array}$ & $\begin{array}{l}\text { Nuevo sistema de vigilancia e } \\
\text { interceptación de llamadas El } \\
\text { Guardián }\end{array}$ \\
\hline Transparencia Activa & $\begin{array}{l}\text { Al día de la solicitud no figuraba } \\
\text { lo solicitado en la Web del MI }\end{array}$ \\
\hline Transparencia Pasiva & $\begin{array}{l}\text { Corresponde presentar solicitud } \\
\text { de acceso a la información } \\
\text { pública }\end{array}$ \\
\hline Procedimiento Administrativo Especial & Ante el Ministerio del Interior \\
\hline Competencia para decidir & Ministerio del Interior \\
\hline Plazo para decidir & $\begin{array}{l}20 \text { días hábiles (más prorroga } \\
\text { en caso de proceder) }\end{array}$ \\
\hline
\end{tabular}




\begin{tabular}{|c|c|}
\hline Acto administrativo del sujeto obligado & $\begin{array}{l}\text { La información solicitada está } \\
\text { calificada como secreta y en el } \\
\text { caso concreto como reservada. } \\
\text { Así lo entendió por el art. } 33 \text { del } \\
\text { TOCAF y el Tribunal de Cuentas } \\
\text { cuando aprobó sin } \\
\text { observaciones el procedimiento } \\
\text { de compra. Citó doctrina acerca } \\
\text { del derecho a la seguridad y el } \\
\text { art. } 70 \text { de la Constitución, así } \\
\text { como la ley } 18.494 \text { del año } 2009 \\
\text { sobre la búsqueda de mejores } \\
\text { tecnologías para el "control y } \\
\text { prevención de lavado de activos } \\
\text { y de financiamiento del } \\
\text { terrorismo" y el art. } 5 \text { que que } \\
\text { transcribió. Citó el decreto } \\
452 / 2009 \text { acerca de las políticas } \\
\text { de seguridad }\end{array}$ \\
\hline $\begin{array}{l}\text { Acción de acceso a la información } \\
\text { pública }\end{array}$ & Justicia competente \\
\hline $\begin{array}{l}\text { Procedimiento de primera instancia } \\
\text { /Sentencia: Juzgado Letrado de } \\
\text { Primera Instancia en lo Contencioso } \\
\text { Administrativo }\end{array}$ & $\begin{array}{l}\text { Se encuentra entonces que la } \\
\text { información solicitada por la } \\
\text { accionante, se encuentra } \\
\text { comprendida en los arts. } 8^{\circ}, 9^{\circ} \text {, } \\
10^{\circ} \text { de la ley } 18.381 \text {. El "silencio } \\
\text { positivo" no autoriza sin más al } \\
\text { juez a disponer que se informe } \\
\text { según lo pedido. }\end{array}$ \\
\hline $\begin{array}{lrr}\text { Procedimiento } & \text { de } & \text { segunda } \\
\text { instancia/Sentencia: } & \text { Tribunal de } \\
\text { Apelaciones en lo Civil } & & \end{array}$ & $\begin{array}{l}\text { Parece obvio que el secreto de } \\
\text { la operación de adquisición del } \\
\text { sistema operativo "guardián", } \\
\text { avalado por el Tribunal de } \\
\text { Cuentas, radica no solamente } \\
\text { en la compra en sí misma (que, } \\
\text { incidentalmente, no fue oculta) } \\
\text { sino que también alcanza a las } \\
\text { características técnicas del } \\
\text { producto adquirido, por simples } \\
\text { razones de seguridad y } \\
\text { protección de los derechos de } \\
\text { todos los habitantes que se } \\
\text { busca tutelar mediante la } \\
\text { prevención y represión de } \\
\text { ilícitos, a través del empleo de } \\
\text { instrumentos como el adquirido. } \\
\text { Confirmase la sentencia } \\
\text { apelada, sin especial condena } \\
\text { en costas ni costos de la alzada. }\end{array}$ \\
\hline
\end{tabular}

\section{CASO PRÁCTICO "PUERTO DE AGUAS PROFUNDAS": INFORMACIÓN SOBRE EL PROYECTO Y VIAJES AL EXTRANJERO DE COMISIÓN INTERMINISTERIAL}

En marzo de 2015, se promueve un procedimiento administrativo ante la Corporación Nacional para el Desarrollo (CND), a los efectos de solicitar información sobre el Proyecto del Puerto de Aguas Profundas y sobre los viajes al extranjero de los integrantes de una comisión interministerial 
que funcionaba en la órbita del mismo, en el período comprendido entre el 15 de noviembre de 2012 y el 28 de febrero de 2015 (http://www.elpais.com.uy/informacion/gobierno-nego-datos-estudiospuerto.html).

Los actores explicaron que a la comisión "oficialmente, se le asignaron US\$700.000 solo para los estudios que pretendía llevar a cabo pero, si se agregan otros gastos incurridos en sus actividades, se debe haber pasado fácilmente el millón de dólares".

La CND respondió el pedido con una carta fechada el 19 de mayo que lleva la firma de su vicepresidente Pablo Gutiérrez y del director Carlos Camy. En ella se señala que en un convenio firmado en agosto de 2012 entre el Ministerio de Trabajo y la CND para establecer la modalidad en la que se realizarían los estudios se estableció "la confidencialidad de toda la información a la que CND tenga acceso para el cumplimiento del mismo".

En consecuencia, en sede administrativa, la solicitud de los ambientalistas realizada, al amparo de la ley 18.381 de acceso a la información pública, fue denegada.

\section{Cuadro Bachetta, Víctor C/ Corporación Nacional para el Desarrollo (CND) Información Pública}

\begin{tabular}{|l|l|}
\hline Sujeto activo & Víctor Bachetta \\
\hline Sujeto Pasivo & $\begin{array}{l}\text { Corporación Nacional para el } \\
\text { Desarrollo (CND) }\end{array}$ \\
\hline Sitio Web & www.cnd.org.uy \\
\hline $\begin{array}{l}\text { Descripción clara de } \\
\text { la información requerida }\end{array}$ & $\begin{array}{l}\text { Estudios sobre el puerto de } \\
\text { aguas profundas y gastos de la } \\
\text { Comisión Interministerial }\end{array}$ \\
\hline Transparencia Activa & $\begin{array}{l}\text { Al día de la solicitud no figuraba } \\
\text { lo solicitado en la Web de la } \\
\text { CND. }\end{array}$ \\
\hline Transparencia Pasiva & $\begin{array}{l}\text { Corresponde presentar solicitud } \\
\text { de acceso a la información } \\
\text { pública }\end{array}$ \\
\hline Procedimiento Administrativo Especial & \begin{tabular}{l} 
Ante la CND \\
\hline Competencia para decidir
\end{tabular} \\
\hline Plazo para decidir & $\begin{array}{l}\text { CND días hábiles (más prorroga } \\
\text { en caso de proceder) }\end{array}$ \\
\hline Acto administrativo del sujeto obligado & $\begin{array}{l}\text { La CND respondió el pedido con } \\
\text { una carta fechada el 19 de } \\
\text { mayo de 2015 argumentando } \\
\text { que en un convenio firmado en } \\
\text { agosto de 2012 entre el MTSS y } \\
\text { la CND para establecer la } \\
\text { modalidad en la que se } \\
\text { realizarían los estudios se } \\
\text { estableció "la confidencialidad } \\
\text { de toda la información a la que } \\
\text { CND tenga acceso para el } \\
\text { cumplimiento del mismo" }\end{array}$ \\
\hline $\begin{array}{l}\text { Acción de acceso a la información } \\
\text { pública }\end{array}$ & \begin{tabular}{l} 
Justicia competente \\
\hline
\end{tabular} \\
\hline
\end{tabular}




\begin{tabular}{|l|l|}
\hline $\begin{array}{l}\text { Procedimiento de primera instancia } \\
\text { /Sentencia: Juzgado Letrado de } \\
\text { Primera Instancia en lo Civil }\end{array}$ & \\
\hline $\begin{array}{l}\text { Procedimiento de segunda } \\
\text { instancia/Sentencia: } \text { Tribunal de } \\
\text { Apelaciones en lo Civil }\end{array}$ & \\
\hline
\end{tabular}

\section{CONCLUSIONES}

El "secreto de Estado" en tanto regla ante el acceso a la información pública tiende a desaparecer con el triunfo del neoconstitucionalismo que nos hace ver el ordenamiento jurídico desde la óptica de los derechos humanos.

Hemos estudiado la acción de acceso a la información pública desde el punto de vista teórico y práctico, en tanto proceso de rango constitucional, señalando la importancia de que rige por igual a personas públicas estatales y no estatales, de que su nota característica es la celeridad que se quiere imprimir con plazos procesales relativamente breves, y hemos puesto énfasis en la necesidad de poner en conocimiento a terceros titulares de la información, instancia no prevista en la Ley.

En los principales pronunciamientos judiciales que hemos repasado, debemos destacar que el Poder Judicial no ha sido ajeno a la importancia del acceso a la información pública y el ejercicio de un derecho humano fundamental, lo que no necesariamente implica que las sentencias sean siempre favorables a las peticiones.

En tal sentido así como en el caso práctico "Aratirí" que hemos analizado, la justicia se pronunció a favor del acceso a la información; en el caso "El Guardián" primó el secreto y la reserva del nuevo sistema de vigilancia de telecomunicaciones por sobre la publicidad del mismo.

Entendemos que el verdadero problema al cual asistimos hoy en día no es que exista información secreta, reservada o confidencial, - siempre existió información de este tipo- en la medida de que es lógico que determinada información no sea de acceso público; sino que radica fundamentalmente en la falta de fundamentación y motivación de tales límites a la información pública, en el entendido de que no alcanza con decir que no podemos acceder a determinada información porque es secreta, reservada o confidencial, tenemos que decir por qué es secreta, reservada o confidencial.

\section{REFERÊNCIAS}

DELPIAZZO, Carlos E. "Dignidad humana y Derecho". Universidad de Montevideo, Facultad de Derecho, Montevideo, 2001.

"A la búsqueda del equilibrio entre privacidad y acceso" en "Protección de Datos Personales y Acceso a la Información Pública" Dr. Carlos Delpiazzo- Coordinador, Instituto de Derecho Informático, Facultad de Derecho de la Universidad de la República, F.C.U./AGESIC, Montevideo 2009).

"De la publicidad a la transparencia en la gestión administrativa", en Revista de Derecho de la Universidad de Montevideo (Montevideo, 2003), Año II, №3, pág. 113 y siguientes. 
DURÁN MARTíNEZ, Augusto. "Neoconstitucionalismo y Derecho Administrativo". LA LEY Uruguay. Buenos Aires, 2012.

"En torno al neoconstitucionalismo" en Estudios Jurídicos, $\mathrm{N}^{\circ} 7$; Universidad Católica del Uruguay, Facultad de Derecho, Montevideo, 2009.

"El derecho administrativo entre legalidad y derechos fundamentales" en DURÁN MARTÍNEZ, A., Estudios de Derecho Público, Vol. II; Montevideo, 2008.

"El derecho al honor también existe" en DURÁN MARTÍNEZ, A., Estudios sobre derechos humanos (Universidad Católica del Uruguay/Ingranusi Ltda.., Montevideo 1999).

"Derecho a la protección de datos personales y al acceso a la información pública Hábeas Data, Leyes $N^{\circ} 18.331$, de 11 de agosto de 2008 y № 18.381, de 17 de octubre de 2008" (A.M.F., 2 Edición actualizada y ampliada), Montevideo 2012.

"El secreto de las actuaciones sumariales no alcanza al sumariado" en Estudios de Derecho Administrativo. La Ley Uruguay, 2010, № 2, pág. 753.

"Límites al acceso a la información pública" en la Revista La Ley Uruguay (Año V, № 1, Montevideo 2012).

HAF, Simone. "Acceso a la información pública y periodismo en México" (México D.F., Octubre 2006), Centro de Competencia en Comunicación para América Latina, www.c3fes.net.

Índice de Transparencia Activa en Línea (ITAeL) "El Estado uruguayo y la provisión de información pública a través de la web" ( $1^{\circ}$ Edición: Centro de Archivo y Acceso a la Información Pública/Instituto de Estudios Legales y Sociales del Uruguay), 2010.

MENDEL, Toby. "Freedom of Information. A comparative Legal Survey", Unesco, citado en Índice de Transparencia Activa en Línea (ITAeL) - "El Estado uruguayo y la provisión de información pública a través de la web" (1 Edición: Centro de Archivo y Acceso a la Información Pública/Instituto de Estudios Legales y Sociales del Uruguay), 2010.

NAHABETIAN BRUNET, Laura. "Acceso a la información pública: pilar fundamental del buen gobierno" (Amalio Fernández, Montevideo 2010).

OCHS, Daniel. "Acceso a la información en poder del Estado y restriccion

es fundadas en la confidencialidad" en "Protección de Datos Personales y Acceso a la Información Pública" Dr. Carlos Delpiazzo- Coordinador, Instituto de Derecho Informático, Facultad de Derecho de la Universidad de la República, F.C.U./AGESIC, Montevideo 2009).

RISSO FERRAND, Martín. "Algunas reflexiones sobre los derechos al honor, a la intimidad, a la propia imagen y a la libertad de prensa" en Anuario de Derecho Constitucional Latinoamericano (Montevideo, 2002).

RUOCCO, Graciela. "Límites a las restricciones a la libertad de expresión" en Estudios de Derecho Administrativo, LA LEY Uruguay, Buenos Aires, 2011, № 3, pp. 279 a 316.

SCHIAVI, Pablo. "Procedimiento administrativo especial: ruta de acceso a la información pública" en Estudios de Derecho Administrativo 2014- № 10; Director: Augusto Durán Martínez - Coordinador: Pablo Schiavi (La Ley Uruguay. Montevideo, 2014), pág. 399 y siguientes.

"Estudios de Información Pública y Datos Personales", Recopilación de trabajos de investigación de los cursos de postgrado 2012-2013. Coordinador. Universidad de Montevideo Facultad de Derecho, Montevideo 2014. 
"Reflexiones a cinco años de la Ley de Acceso a la Información Pública en el Uruguay" en Estudios de Derecho Administrativo № 9/2014 - Director Augusto DURÁN MARTíNEZ, Coordinador Pablo SCHIAVI (La LEY URUGUAY. Montevideo, 2014), pág. 181 y siguientes.

"Límites al acceso a la información pública en la minería de gran porte" en Estudios de Derecho Administrativo 2014- № 9; Director: Augusto Durán Martínez - Coordinador: Pablo Schiavi (La Ley Uruguay. Montevideo, 2014), pág. 381 y siguientes.

"El Control del Acceso a la Información Pública y de la Protección de Datos Personales en el Uruguay”, Universidad de Montevideo - Facultad de Derecho, Montevideo 2012.

"El Acceso a la Información Pública en el Uruguay" en Estudios de Derecho Administrativo, № $\overline{3 / 2011}$ - Director Augusto DURÁN MARTíNEZ, Subdirector Carlos GUARIGLIA, Coordinadores Pablo SCHIAVI, Bruno BERCHESI, Germán GUARIGLIA (La LEY URUGUAY. Buenos Aires, 2011), pág. 393 y siguientes.

$\neg$ ᄀ___ “El Acceso a la Información Pública en el Uruguay" en el Anuario da Facultade de Dereito da Universidade da Coruña, №15, (Universidade da Coruña, 2011), pág. 147 y siguientes.

"El Acceso a la Información Pública en el Uruguay" en la Revista Argentina del Régimen de la Administración Pública, Año XXXIV, № 397 (R.A.P., 2011) pág.13 y siguientes.

UNIDAD DE ACCESO A LA INFORMACIÓN PÚBLICA. Sitio Web: http://www.informacionpublica.gub.uy.

UNIDAD REGULADORA Y DE CONTROL DE DATOS PERSONALES. Sitio Web: http://www.datospersonales.gub.uy.

VÁZQUEZ PEDROUZO, Cristina. "El régimen jurídico del acceso a la información pública y la protección de datos personales" (Revista de Derecho y Tribunales, № 15, A.M.F., Montevideo 2011).

\section{COMO CITAR ESSE DOCUMENTO}

SCHIAVI, Pablo. Régimen Jurídico de la acción de acceso a la información pública en el Uruguay. Revista do Direito, Santa Cruz do Sul, v. 2, n. 49, set. 2016. ISSN 1982-9957. Disponível em: $<$ https://online.unisc.br/seer/index.php/direito/article/view/7910>. Acesso em: doi:http://dx.doi.org/10.17058/rdunisc.v2i49.7910. 